\title{
9. DEFORMATION STRUCTURES AT SITE 808, NANKAI ACCRETIONARY PRISM, JAPAN ${ }^{1}$
}

\author{
A.J. Maltman, ${ }^{2}$ T. Byrne,${ }^{3}$ D.E. Karig, ${ }^{4}$ S. Lallemant, ${ }^{5}$ R. Knipe,${ }^{6}$ and D. Prior ${ }^{7}$
}

\begin{abstract}
The toe of the Nankai accretionary prism, south Japan, was cored at Ocean Drilling Program Site 808, and a range of exceptionally well-developed deformation structures was revealed. This paper documents their appearance at the optical microscopic scale. Bedding fabrics, largely because of gravitational consolidation, perhaps with some tectonic contribution, increase in intensity with burial depth, but this is irregular, partly because of the effects of bioturbation. Small folds in the slope apron sediments are thought to represent gravitational mass movement, but rare similar structures now deeply buried in the prism may have the same origin.

The most common structures are grouped into a family termed deformation bands. These include true kinks, shear zones, and very narrow zones of phyllosilicate-preferred orientation called faults, but range through many structures with intermediate attributes. Despite this gradational aspect, the main types of deformation bands are thought to originate independently, according to the mechanical conditions operative at the time, rather than by a progressive evolution. The shear zones and faults show complex substructures and interrelationships and are dominant in the Nankai prism at depths not previously drilled.

Whereas features such as the vein structures occurring at $640 \mathrm{mbsf}$, a hydraulic breccia at $800 \mathrm{mbsf}$, and subtle textures in the décollement zone owe their origin primarily to overpressuring, the deformation bands reflect focused tectonic deformation in the prism, a direct result of plate convergence.
\end{abstract}

\section{INTRODUCTION}

Accretionary prisms, forming at convergent plate margins through the offscraping of material from the subducting plate, represent one of Earth's most active deformational environments. The overall structure of the prisms and the general nature of the deformation processes are now reasonably well known, but many questions remain and detailed knowledge is sparse. For example, deformation features at the core scale are being increasingly reported, but their nature, distribution, and origin are still poorly understood. Reports on various structures are scattered throughout Deep Sea Drilling Project (DSDP) and Ocean Drilling Program (ODP) reports; not all of them are known to be of tectonic origin. Lundberg and Moore (1986) provided an overview of the deformation structures known at that time. It is noticeable that many of the examples in that summary were drawn from the Nankai prism of south Japan.

On Leg 131 we were concerned with the Nankai accretionary prism. Numerous deformation structures were recovered by the drilling, and the structural geology group was able to document them in unprecedented detail. Most of the macroscopic deformation structures reported from accretionary prisms previously drilled by DSDP and ODP are present at Nankai, and some of them are exceptionally numerous and well developed.

The shipboard appearance of the core-scale structures, together with their distribution with depth and their orientations, were outlined in Taira, Hill, Firth, et al. (1991). That the structures recorded little evidence of their having acted as fluid conduits or barriers, consistent with an overall pervasive dewatering of the Nankai prism, is reported

\footnotetext{
${ }^{1}$ Hill, L.A., Taira, A., Firth, J.V., et al., 1992. Proc. ODP. Sci, Results, 131: College Station, TX (Ocean Drilling Program)

${ }^{2}$ Institute of Earth Studies, University College of Wales, Aberystwyth, Wales SY23 3DB, United Kingdom.

${ }^{3}$ Department of Geology and Geophysics, University of Connecticut, 354 Mansfield Road, Storrs, CT 06269-2045, U.S.A.

${ }^{4}$ Department of Geological Sciences, Comell University, Ithaca, NY 14853-1504, U.S.A

${ }^{5}$ Laboratoire de Geologie, Ecole Normale Superieure, 24 Rue Lhomond, 75231 Paris, Cedex 05, France.

${ }^{6}$ Department of Earth Sciences, University of Leeds, Leeds LS2 9JT, United Kingdom.

${ }^{7}$ Department of Earth Sciences, University of Liverpool, Liverpool L69 3BX. United Kingdom,
}

in Maltman et al. (this volume). Stress tensor analysis based on the deformation structures is reported by Lallemant et al. (this volume). Land-based work has provided further information on the extent to which the deformation structures interacted with the fluids of the prism, and this is presented in Byrne et al. (this volume). A range of microchemical and electron microscopic studies of the structures is planned and will be reported separately.

The present paper is concerned with the appearance, geometry, and mechanics of the deformation structures in the light of the detailed optical microscopic investigations that have been carried out. The first part of the article addresses the problem of terminology and classification of some of the structures, not for reasons of pedantry, but to facilitate comparison with structures reported from other drilling efforts, including those in the future. Descriptive features of each of the structures are presented in turn, and remarks on the possible origins of the structures are dealt with separately in a final section. All the thin sections examined have been cut, as far as possible, normal to the structures, which in most cases is their movement direction.

\section{TECTONIC SETTING OF SITE 808}

Leg 131 consisted of a single site, 808 , at which five holes were drilled (Taira, Hill, Firth, et al., 1991). Figure 1A shows a map with the location of Site 808. Hemipelagic sediments of the Shikoku Basin, a young backarc basin developed within the Philippine Sea Plate, are converging at about $4 \mathrm{~cm} / \mathrm{yr}$ toward southwest Japan, a collage of island arc and earlier accretion systems now part of the Eurasian Plate (Taira et al., 1989, and references therein). Part of the hemipelagite sequence is being underthrust, but the upper part is being offscraped and incorporated into the Nankai prism.

At the same time, the trench immediately oceanward of the prism, the Nankai Trough, has been receiving large amounts of clastic material from the recently uplifted parts of Japan, and these sediments, too, are being offscraped into the Nankai prism. The offscraped materials are separated from those being underthrust by the basal décollement of the prism. The approximate oceanward limit of deformation within the prism is shown as a barbed trace on Figure 1A, so Site 808 , being just landward of the trace, lies at the outer toe of the Nankai prism. Also shown on Figure 1 A are Sites 297 and 298, drilled during DSDP Leg 31, and Sites 582 and 583 from DSDP Leg 87. The 


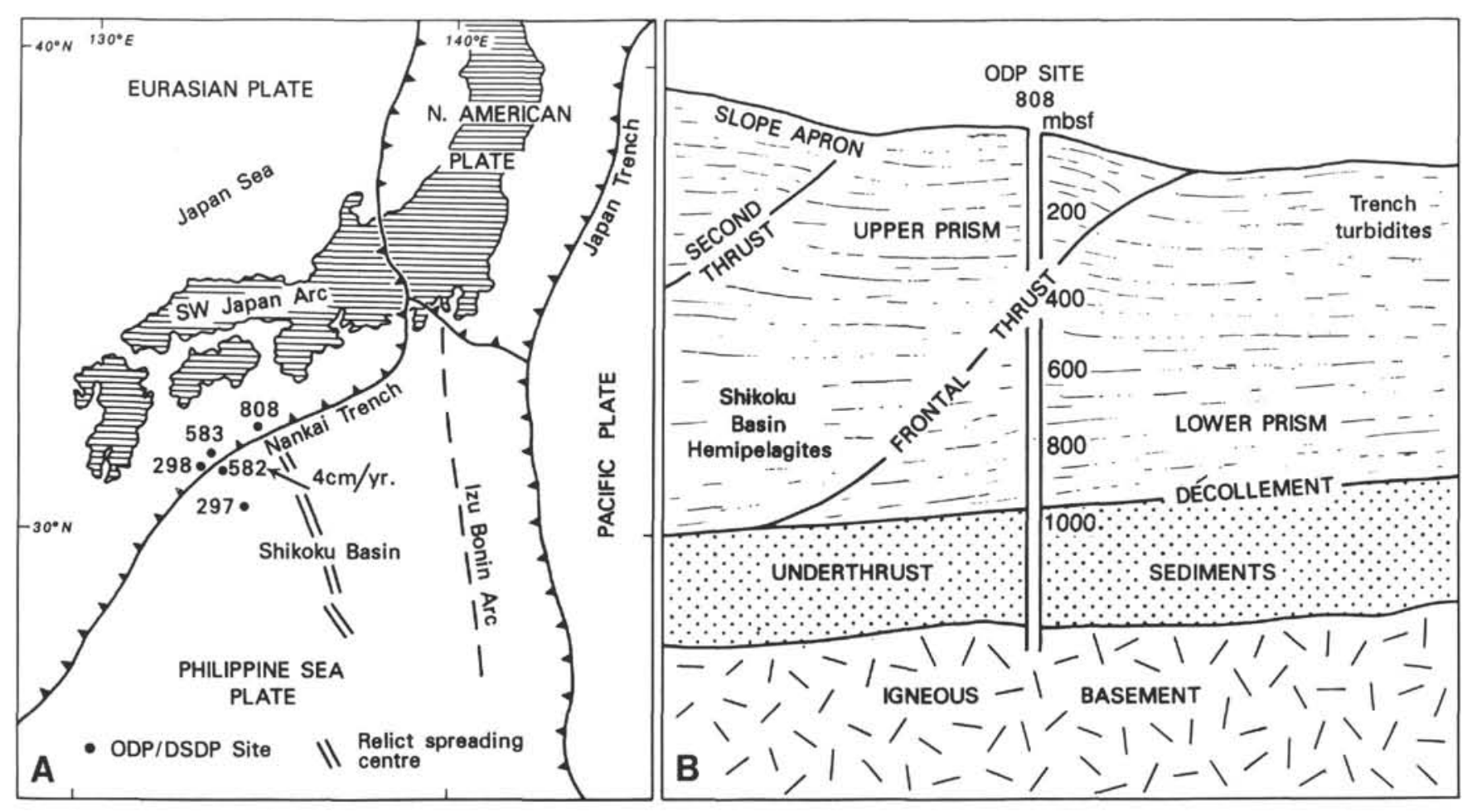

Figure 1. A. Map showing the location and plate tectonic setting of ODP Site 808 and earlier DSDP drilling sites. B. Generalized cross section showing the main elements of the toe region of the Nankai prism penetrated at Site 808.

Leg 31 sites were spot cored only. At Site 583 the prism was cored to $450 \mathrm{mbsf}$; it provides an interesting comparison of the microstructures at these higher levels of the prism, and Site 582 is valuable as a reference hole, having reached a depth of $750 \mathrm{mbsf}$ in the undeformed sediments oceanward of the prism.

The offscraping process is taking place by the propagation upward and oceanward from the décollement of a series of thrusts, in the general manner now well established for prism growth. It is one of the attractions of the Nankai area that the plate convergence and prism accretion are geometrically fairly simple-being almost orthogonal-despite the singular complexity of the regional plate tectonic setting (Taira et al., 1989). The large-scale structure of the prism in the Site 808 area is clearly seen on the seismic profiles presented by Moore et al. (1990, 1991) and Moore et al. (this volume).

Site 808 was designed to pass through the present frontal thrust of the prism (Fig. 1B). This entailed penetrating the slope apron deposits and that part of the prism above the thrust, referred to here as the upper prism. Core was successfully recovered from these portions, together with representative material from the thrust itself. What will be referred to here as the lower prism was also cored, including the largely turbiditic sediments of the trench wedge and the underlying hemipelagic sediments of the Shikoku Basin. Drilling at Site 808 penetrated both the décollement zone and the underthrust hemipelagite, and reached the underlying igneous oceanic basement. Therefore, with an overall core recovery rate greater than $50 \%$, it was possible to document the nature of the structures throughout the depth of the prism and the underthrust sediments. The mechanical state of the material destined to be subducted, containing only a few minor faults, contrasts with the intensity of deformation in the prism (Taira, Hill, Firth, et al., 1991, p. 119-120), and so receives little attention in this paper.

\section{BEDDING FABRICS}

Bedding is discernible in many of the cores, through changes in lithology. The variations in bedding dip angle with depth are shown in Figure 2. Two zones of dramatically increased dips occur, which coincide exactly with the frontal thrust and décollement zones. The bedding dips in the frontal thrust zone reveal a reclined anticline-syncline pair associated with the thrusting (Taira, Hill, Firth, et al., 1991, Fig. 63) but any such folding in the décollement is now masked by the intense brecciation, which seems to be primarily responsible for the bedding orientations as they now exist in that zone.

Anomalously steep dips are also recorded at about 530 and 800 mbsf, depths at which other features suggestive of increased deformation are recorded (see "Distribution of Structures" section, this chapter). We suggest there that these may well represent zones of increased strain, perhaps incipient or failed thrusts.

The other aspect of bedding relevant to the present context is that in many cores a parallel orientation of inequant grains, such as detrital phyllosilicates and authigenic clays, produces a bedding-parallel fabric quite independent of deformation, and hence referred to here as a primary sedimentary fabric (PSF). It is most apparent in cores from deeper levels, which tend to break readily along it; that is, it is expressed as a fissility.

However, the PSF is weak or lacking in bioturbated sediments, and as these are particularly common in the Shikoku Basin hemipelagite, which now form the deeper parts of the prism, the increase in intensity of the PSF with depth is irregular. Furthermore, the intensity of PSF development appears to be a factor in allowing the production of some of the deformation structures to be discussed below, so bioturbation also tends to obscure indirectly the distribution of deformation structures with depth.

\section{SLUMP FOLDS}

Centimeter-scale reclined and recumbent folds were reported and illustrated in Taira, Hill, Firth, et al. (1991). All were from the slope apron deposits veneering the present-day prism. However, the landbased microstructural work has revealed examples of similar structures within the prism such as at $426 \mathrm{mbsf}$, in the trench wedge 

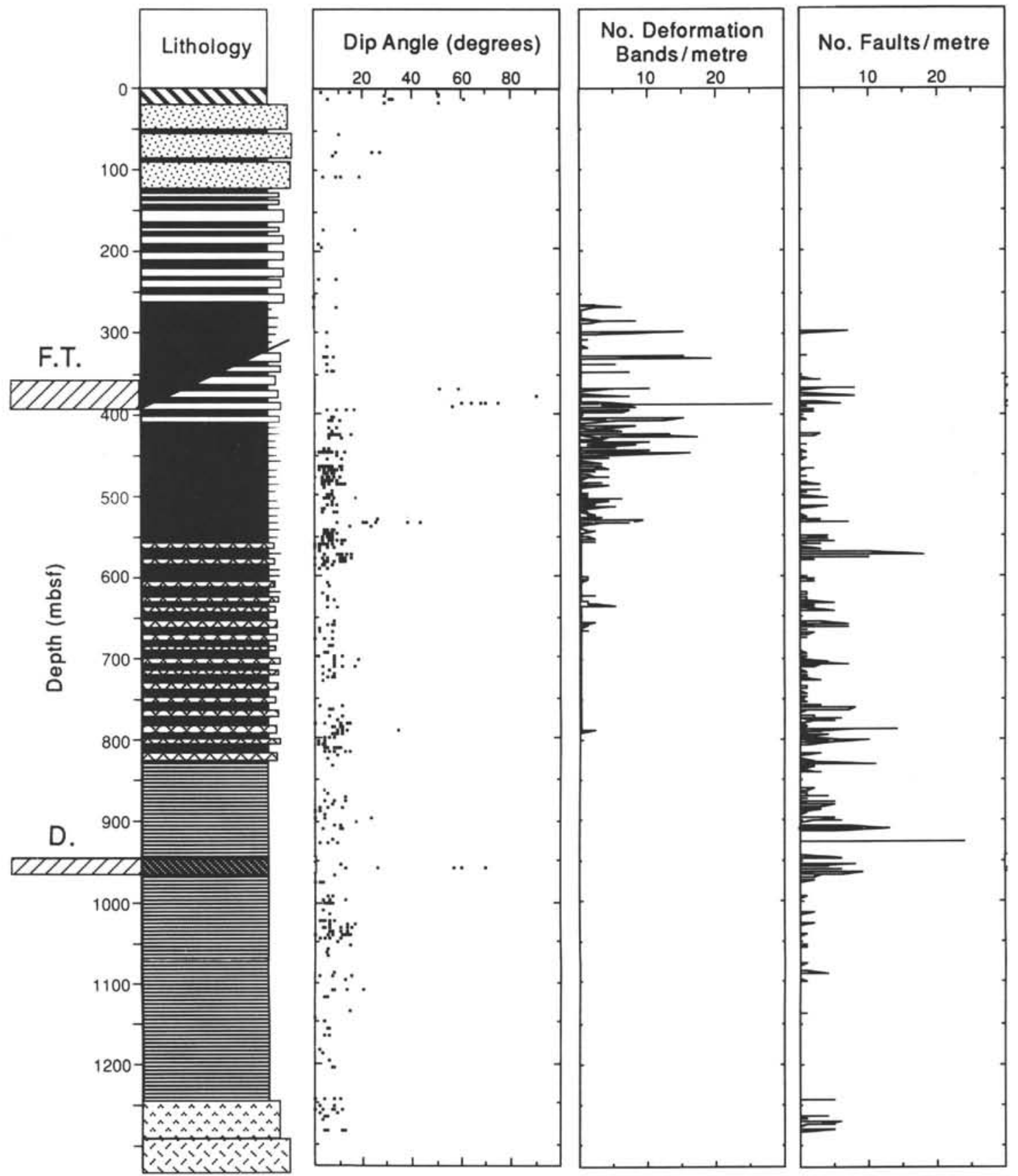

Figure 2. Distribution with depth at Site 808 of lithology, deformation bands, and faults, as distinguished while we were aboard ship. The lithological symbols, from top to bottom, are: diagonal stripes = slope apron muds and sands; stipple = sand turbidites; gray tint/white $=$ hemipelagite with thin silt and sand turbidites; pecks $=$ ash/tuff; horizontal rule $=$ hemipelagic mud. The two lowermost units are acid volcaniclastic deposits overlying basaltic basement. F.T. is the frontal thrust zone, and D. the basal décollement zone.

deposits, and considerably below the frontal thrust. An example of what appears to be a fold closure of similar appearance is preserved in material from within the décollement zone. No fabrics have been seen directly associated with any of these structures - the only folds possessing an axial-planar fabric are those lying parallel to bedding.

\section{DEFORMATION BANDS}

Numerous roughly planar structures, oblique to bedding, are seen in the cores from Site 808. In places they show displacement of preexisting markers, showing their deformational origin. Most of them show at the microscopic scale some degree of deflection of the primary bedding fabric. Considerable difficulty was met while aboard ship in efficiently classifying these structures for the purposes of the core descriptions, largely because of all the subtle variations in appearance. In fact, subsequent land-based work reveals that their variation in appearance is even greater than suspected.

Terminology difficulties arise both from agreeing on a nomenclature that adequately covers the range of structures, while being reasonably simple and maintaining some correlation with structures described by previous workers. Names that have been applied in the past to structures such as these include shear bands, shear zones, kink 
bands, deformation bands, and faults. The variation in appearance of the structures is such that no single term is very meaningful, but neither can they be neatly subdivided into a series of "pigeonholes." Some attributes of one kind of structure can be present in another type, but there is not complete gradation between the different types.

The term "deformation band" is used here in a general way for all the core-scale and smaller structures that are essentially planar and involve some degree of displacement along them. It covers a range of features. Probably all the previous terms listed above are subsumed within this name, but features such as vein structure and fissility are not included. The two names employed during the shipboard descriptions, fault and shear band, are now included within the family of deformation bands; however, the term shear band has now been discarded because of implications it may carry from its usage in completely different materials, such as mylonites.

Examples of deformation bands that are sufficiently distinctive to be specified as kink bands, shear zones, and faults are referred to as such, but there are many instances where a given band shows the characteristics of more than one kind of structure and is in some ways intermediate in appearance. For example, some faults show in places the substructure characteristic of shear zones, and such features can also occur in bands that are essentially kinks. We refer to such structures as kink-like, shear zone-like, or fault-like varieties of deformation band, according to the dominant attributes of the structure. Characteristics of the main types are described in the following sections.

\section{Kink Bands}

Kink-like deformation bands are common at Nankai, particularly in the parts of the prism above about $500 \mathrm{mbsf}$. Some are true kinks, merely being sharp deflections of the PSF. We concur with the description of kink bands provided by Lundberg and Karig (1986) and Lundberg and Moore (1986). It is interesting to note that apart from a remark by Lundberg and Moore (1986) on the Aleutian Trench, all the examples of kink bands so far documented come from Nankai. Those described previously are from Sites 298 of DSDP Leg 31 and 583 of DSDP Leg 87, both within the prism.

In summary, these structures are more planar and are broader (0.5-3 mm width) than other deformation bands. Macroscopically, they are visible as bands darker than the host material, in places slightly deflecting laminations. Microscopically, they are inconspicuous. The color difference in plane-polarized light is subtle (PI. 1, Fig. 1), and only the extinction pattern between crossed nicols discloses the deflection of the bedding-parallel fabric. Lundberg and Karig (1986) presented a series of photomicrographs in plane and partially polarized light of examples from Site 583 that adequately illustrate the general nature of kink bands.

The margins of the bands are not sharp in detail - there is a narrow zone of curvature- but the deflection of the PSF in these true kinks is only about 300 , and there is no substructure developed (PI. 1, Fig. 2). In all examples where deflection across the band is discernible, the structures show a reverse sense of movement. These kink bands typically occur in isolated sets, that is, without other deformation structures being present.

Much more common are structures essentially of kink-like geometry but with some degree of substructure, and typically occurring spatially associated with shear zones. As discussed later, these kinklike bands most commonly terminate against the shear zones, but some examples pass through the shear zones and in other instances are displaced. As a whole the kinks are oriented at a high angle to bedding, and hence to the shear zones that themselves are generally of shallow inclination. Core-scale examples are illustrated in Taira, Hill, Firth, et al. (1991, fig. 54). The orientation of these kink-like deformation bands is typically in the range $50^{\circ}-60^{\circ}$, although some examples are as low as $28^{\circ}$ from horizontal. The deflection angle ranges between $13^{\circ}$ and $56^{\circ}$.
Some kink-like bands are curviplanar, and as a result merge with adjacent examples. Some splay and anastomose, with an internal geometry more complex than simple planar kinks. Varying degrees of internal volume loss seem to be implied, and in line with this, the width of the zones varies, so that in places they pinch to a shear zone-like narrowness. Under the microscope, narrow substructures, inclined to the margins of the band, are visible in places, and the structure resembles a shear zone. Despite these localized complexities, however, the dominant effect is a uniform fabric deflection, and the overall orientation of the bands is at a high angle to bedding.

\section{Shear Zones}

Numerous structures were recovered on Leg 131 that show a greater complexity than the kinks described above and have much in common with the structures well known from other settings as shear zones (e.g., Morgenstern and Tchalenko, 1967; Maltman, 1988). They are narrower than kinks, have a more irregular and complex geometry, and show an intricate substructure. In cores, they are seen as narrow, wavy traces, commonly anastomosing, and in places displacing preexisting features. Usually it is their differentiation from faults that is more arguable than their distinction from kink bands.

A typical microscopic appearance is sketched in Figure 3. Any color difference is very faint; it is the appearance between crossed nicols that is striking. The narrow, sharply bounded zones of intense fabric reorientation show brightly against the darkened host material. Especially when viewing with the one-wavelength accessory plate, a host of substructures is apparent (PI. 1, Fig. 3). The margins may consist of very narrow, parallel subzones of reoriented phyllosilicates, and there may also be similarly oriented films within the zone. Inclined subzones are common. Where the overall sense of displacement is known, it is clear that some inclined subzones bear the riedel orientation whereas others are in a thrust shear orientation. These further crenulate the deflected fabric within the shear zone. However, most commonly the movement sense, even when viewed at the microscopic scale, is ambiguous.

Grain orientations within the different subzones are variable and show no direct relation with orientations elsewhere. Between the various subzones, quartz grains may have been caught up, and there may be pockets of clayey host material. The fabric within these pockets is of variable orientation and intensity, and is not the same as that of the matrix outside the shear zone. In a number of respects, therefore, the present observations differ from those reported by Karig and Lundberg (1990), presumably because a much wider range of features was encountered at Site 808.

When viewed microscopically, these deformation bands are typically inclined gently in the same direction as bedding, at about $20^{\circ}-30^{\circ}$ from the horizontal, although examples dipping at $60^{\circ}$ are seen around 260 and $533 \mathrm{mbsf}$ (Pl. 2), both layers where the structures are numerous. The conjugate orientation, although seen in the relatively highly strained material shown in Plate 2 , is rarely present in the thin sections examined; in fact, the microscopic orientation data do not fit well with the core measurements summarized in Taira, Hill, Firth, et al. (1991). This may partly reflect the terminology differences from the shipboard work, but it may also be a function of sampling, in that most specimens selected for thin-sectioning showed unusually clearly developed features.

In the examples studied, the Riedel subshears are oriented to the shear zone margins between $12^{\circ}$ and $17^{\circ}$, and to the thrust subshears between $24^{\circ}$ and $54^{\circ}$. No correlation with depth or bulk physical properties is apparent; these angles could include some modification by slight rotation rather than initial values.

Broad, highly irregular zones probably comprise arrays of shear zones that have coalesced and presumably represent substantial local shear strains. Both these and individual zones can show markers displaced by very large magnitudes relative to their width, and the structures approach faults in characteristics. 


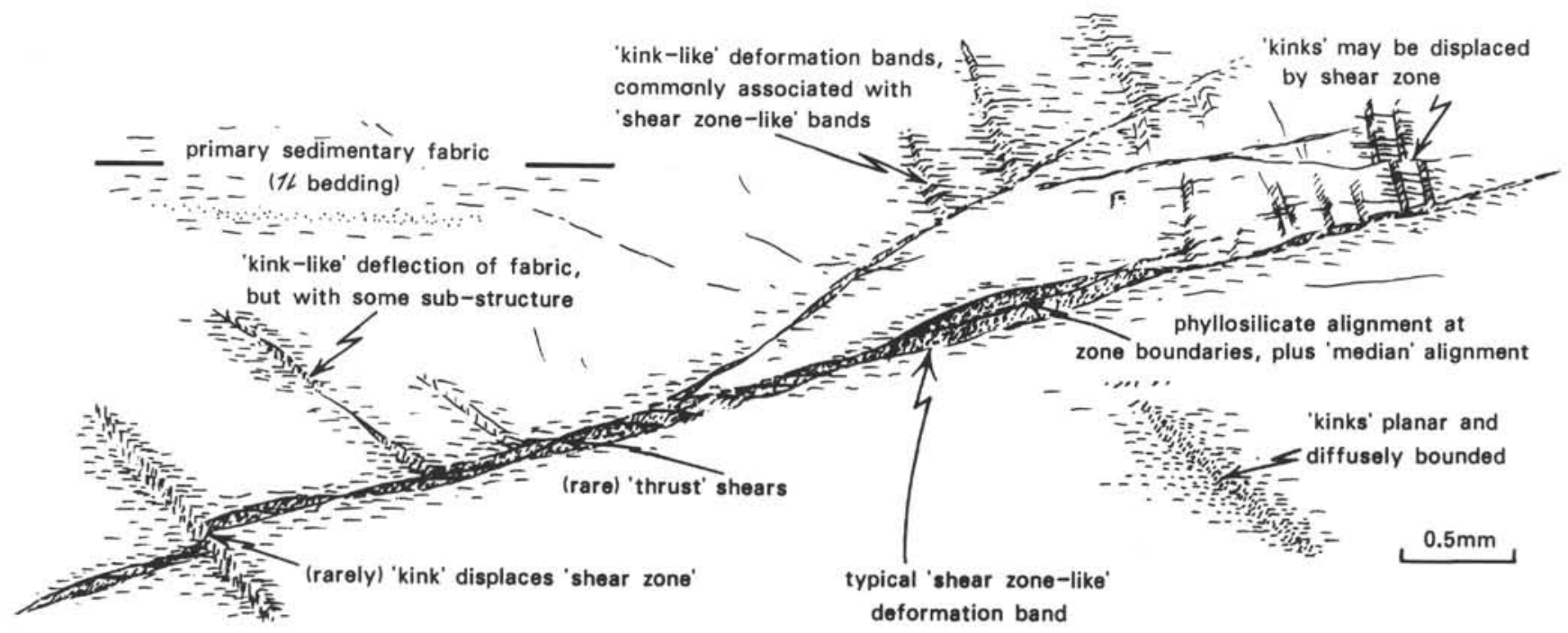

Figure 3. Sketch showing typical features of the shear zone style of deformation band, as viewed at the optical microscope scale.

Faults

These kinds of deformation bands are characterized by their overall narrowness and the large displacement along them. Some examples are approximately planar and resemble very narrow shear zones, although they may coalesce to form a broad fault array. Other examples, especially in high strain zones such as the frontal thrust and décollement, are highly irregular and can reach widths of over a millimeter. At the core scale, the latter examples are conspicuously dark or black in color (see Taira, Hill, Firth, et al., 1991, fig. 62).

The microscopic appearance of the faults is dominated by intense grain orientation parallel to the zone margins, although inclined Riedel and thrust substructures may be visible in places. However, substructures seen in a particular place are commonly just one tiny part of a much broader, compound array of braided faults. A typical appearance is very similar to the fault from the Japan Trench illustrated by Knipe (1986, fig. 12).

The structures are therefore not fractures in the sense that mineralization is recording cohesion loss across the zones; descriptively they are akin to higher strain versions of shear zones. These fault-like deformation bands are therefore not the same as the dilatant, mineralized fractures found in the deeply budded sediments below the prism.

Many faults cross-cut other kinds of deformation bands, although some examples may have formed early in the development of the prism toe. The orientation of the faults is more complex than the other deformation bands. Indeed, it was clear during the shipboard observations that the fault structures variously show reverse, normal, and strike-slip senses of movement. These aspects are taken up in the analysis of Lallemant et al. (this volume).

\section{VEIN STRUCTURE}

The feature that has come to be known as vein structure is now known from several accretionary prisms, but, in contrast with the deformation bands, its development is weak at Nankai. Its appearance corresponds in general with the descriptions given by Lundberg and Moore (1986). In common with these descriptions, the term veins in the present context does not imply the mineralization of fractures: the infilling material is lithologically similar but structurally distinct from the host material.

At about 640 mbsf, several bedding-parallel zones of veins were observed, over an interval of $20 \mathrm{~cm}$. Individual veins are approximately perpendicular to bedding, but show a slight sigmoidal aspect. Under the microscope, the veins are subtle. There is slight dark discoloration evident in plane-polarized light; viewing between crossed nicols shows reorientation of some of the phyllosilicate flakes, but it is not obvious. The orientation is parallel to the vein itself, even at the margins of the structure. Consequently, there is no sign of a sigmoidal deflection of the fabric as it enters the veins. Other, normally finer, particles within the veins appear to be retaining the orientation of the host material; that is, approximately parallel to bedding.

\section{HYDRAULIC BRECCIA}

Brecciated material was observed during the microscopic analysis of two samples from 787.6 mbsf. Fault-like and shear zone-like deformation bands are numerous in the sample (see "Distribution of Structures" section, this chapter), and ramify through the material apparently unsystematically. In places, the structures open up to give pockets in which angular fragments of the wall-rock are detached and disoriented in a matrix of dark, fine-grained material (Pl. 3). SEM examination confirms that much of this matrix is an intergrowth of cryptocrystalline silica and smectite.

\section{DÉCOLLEMENT}

The highly fragmented nature of the décollement zone, described in Taira, Hill, Firth, et al. (1991), made it difficult to sample. Parts of the core are brecciated into irregular, angular pieces, and other parts consist of shiny flakes that resemble scaly clays. The latter were unsuitable for thin-section preparation; optical examinations were made on the larger, intact pieces from the breccia, which by their nature will not represent the sites of greatest deformation.

The texture of some of these pieces under the optical microscope is unusual, but it has proved impossible to record adequately on a photograph. The texture consists of very dimly bounded, roughly oval patches, each about $0.2-0.5 \mathrm{~mm}$ across, and containing a weak fabric oriented slightly differently to the matrix and adjacent patches. The whole texture has a mottled aspect. However, it is subtle, and the disorientations are only really apparent when using an accessory plate and rotating the microscope stage.

Apart from the differences in orientation, the patchiness is reminiscent of bioturbation. However, in some places the margins of a particular patch are defined by narrow shear zones, although the two are not necessarily related genetically. There are no lithological or color differences between the patches and matrix. The texture has not 
been observed elsewhere in the prism. This confinement to the décollement horizon may be signaling that the texture, despite its elusive appearance, may be genetically significant. Electron microscopic examination of the shards from the scaly material reveal complex textures in the décollement zone (Byrne et al., this volume).

\section{DISTRIBUTION OF STRUCTURES}

The overall distribution of core-scale structures is shown in Figure 2 and was discussed in Taira, Hill, Firth, et al. (1991). The following section refines this and makes comments in the light of the land-based studies.

The shallowest tectonic structures observed in the cores are deformation bands occurring at $260 \mathrm{mbsf}$. Their microscopic appearance has all the attributes found in deeper structures, being dominated by kink-like bands with some substructure oriented at a high angle to shear zone-like bands, themselves lying at a low angle to bedding. The shear zones are well developed, showing a braided form and complex substructures, although the kinks are less clear. The host material has only a weakly developed PSF. The only difference is the orientation with respect to the horizontal, but bedding itself dips relatively steeply here-about $20^{\circ}$. The shear zones dip with the bedding, at $35^{\circ}-40^{\circ}$, and the kinks dip, in the opposite direction to bedding, between $27^{\circ}$ and $52^{\circ}$. Riedel substructures within the shear zones are inclined at about $12^{\circ}$ to the zone margins, and the thrust shears at around $50^{\circ}$. Because these structures retain their geometric relation with the steepened bedding, it appears that they, too, have been rotated after their formation by about $20^{\circ}$.

With increasing depth in the upper part of the prism, the kink- and shear zone-like deformation bands become intensely developed, and there is more variation in appearance, although there is no change in essential character. Faults are common in the frontal thrust zone. An observation important for understanding the origin of the deformation bands is that kink and shear zone-like bands appear to have been rotated in the thrust zone, and they are cross-cut by the faults.

The distribution of deformation bands in the lower part of the prism is inhomogeneous, but there is an overall decrease in intensity of development.

In particular, kink-like and shear zone-like structures decrease in number down to about $600 \mathrm{mbsf}$, below which they are sparse and the fault-like structures dominate. The best examples of kink bands sampled occur in materials that show a good primary fabric, for example, at $435 \mathrm{mbsf}$. Shear zones and faults are particularly numerous around $530 \mathrm{mbsf}$ ( $\mathrm{Pl} .2$ ). Bed steepening is also observed at this horizon.

The vein structures were encountered around $640 \mathrm{mbsf}$, in $43 \%$ porosity mudstones, and in a loose piece ("wash" sample) from unknown depth. Otherwise, these structures appear to be absent at Site 808 . It may not be coincidence that the vein structures recorded from Site 582 occurred at between 634 and 644 mbsf, depths almost identical to the Site 808 examples.

Between 777.9 and 802.5 mbsf the shear zones and faults are particularly numerous, and narrow zones of breccia are observed. It was described aboard ship as a fault zone, occurring between 788 and $789 \mathrm{mbsf}$, but it was unclear at that time whether or not the brecciation was drilling-induced. Subsequent microscopic observations have confirmed its natural origin and revealed a greater intensity of development. Samples showing complex deformation bands were taken from $787.6 \mathrm{mbsf}$, and under the microscope these show numerous instances of the breccia pockets not seen in the cores (Pl. 3).

Below this horizon, virtually all of the deformation bands observed can be regarded as faults. They inhomogeneously pervade much of the lower parts of the prism. Aclastic dike occurs at $813 \mathrm{mbsf}$, and was described in Taira, Hill, Firth, et al. (1991), but it has not been analyzed microscopically. The décollement features, between 945 and $965 \mathrm{mbsf}$, were described earlier.
Below the décollement, the striking structural feature is the sheer paucity of examples (Fig. 2). Deformation at this plate convergence zone is very largely confined to the hanging wall-the accretionary prism. The faults that are seen in cores from below the décollement are discrete, approximately planar, very fine zones of abrupt displacement. Their variable geometry and sense of movement further indicates a stress history different from the prism.

Further zones of vein structures were observed around 1252 to $1262 \mathrm{mbsf}$, in the underthrust volcanic-rich hemipelagite, but these proved to be very subtle under the microscope, and of different appearance in detail to the vein structures in the prism. They are horizontal zones of diffusely bounded structures, inclined discontinuously at about $70^{\circ}$ to bedding. The veins are composed of material slightly darker than the host, and they lack the phyllosilicate reorientation that characterizes the high-level vein structures. They occur close beneath layers of welded tuff, with which they are presumably related.

The shallowest veins (in the usual sense of mineralized fractures) observed in the Site 808 cores were at $1275.8 \mathrm{mbsf}$, and Plate 1.6 shows a similar example from $1281.6 \mathrm{mbsf}$. This same sample shows fine, vertical, wavy dark traces that appear to be stylolites. This location, about $316 \mathrm{~m}$ below the décollement and just $8 \mathrm{~m}$ above igneous basement, is the shallowest known example of diffusion mass transfer (pressure solution) having operated as a deformation mechanism at this site.

\section{ORIGIN OF THE STRUCTURES Bedding Fabrics}

Steepened bedding and occasional fold closures in the uppermost parts of the prism are attributed to gravity-induced movements. More deeply buried examples presumably are legacies of some gravitational instability at the time the sediment was at or close to the seafloor. The deformation appears to have taken place entirely by grain boundary sliding; no associated structures have been observed, and none of the folds show secondary axial-planar fabrics.

The primary sedimentary fabric is largely the result of gravitational consolidation, as indicated by its general increase with greater depth of burial, in line with the physical properties data. However, there is some suggestion from acoustic anisotropy (Taira, Hill, Firth, et al., 1991), paleomagnetism (Owens, this volume), and sonic velocity data (Byrne et al., this volume) that tectonic consolidation may have played a part, possibly in the very early stages of accretion. As yet, no microstructural manifestation of this process has been identified, so the water loss may have been wholly pervasive, leaving no record in the grain orientations, or it may have interacted with the earliest, tectonically induced, deformation structures.

The fissility is bedding-parallel, and almost certainly is a response to gravitational consolidation. Bioturbation is an important factor in controlling PSF intensity, having been able to destroy any preexisting phyllosilicate orientation or to have disturbed the sediment to such an extent that no preferred orientation could be induced subsequently. This seems particularly true of the lower prism hemipelagite, while in the similar material below the décollement, overpressuring may also be contributing to unexpectedly weak PSF development.

\section{Deformation Bands}

Many of the shear- and fault-like deformation bands show lineated surfaces, and these form the basis of the stress tensor analysis presented by Lallemant et al. (this volume). This demonstrates a close relation between the stresses responsible for the structures and the plate movement vectors. Because there is a close geometric relationship between these features and other deformation bands, it is clear that this family of structures is of tectonic origin, and many of them are directly the result of plate convergence. 
Kink bands can form as independent structures, isolated from other deformation bands. It is noticeable that all the examples known from Site 808, as well as those illustrated by Lundberg and Karig (1986), are at a high angle to bedding, and that the sediment has a significant PSF. Presumably, these structures reflect some bulk lowangle shortening of the prism, which these highly anisotropic sediments take up by kinking.

Much more commonly, kink-like structures are spatially related to shear zones. Because there are structures that show attributes of both kink bands and shear zones, it is tempting to think that increasing displacement enables kinks to evolve into shears. This may be so in some cases. If a kink finds itself subject to additional shear, increasing rotation and preferred orientation of the phyllosilicates will decrease the width of the band and may induce strain softening. Further displacement then leads to the shear-zone substructures being developed, in the manner discussed by Morgenstern and Tchalenko (1967) and Mandl (1988, p. 75-80). However, such progressive changes are not thought to be the general case.

The most common occurrence of kink-like structures is in spatial association with shear zones. This close relationship suggests they formed together. Moreover, although the kinks commonly terminate against the shear zones, it is rare to be able to find an offset counterpart across the zone, and there are examples of kinks deflecting shear zones. This mutual cross-cutting suggests that the two structures formed at approximately the same time, with only localized loss of synchroneity. The kinks seem to arise from accommodational strains arising from the principal displacement along the shear zone.

This suggestion is supported by experimental evidence, where identical microstructures have been observed in similar geometric relationships (Maltman, 1978). The kink bands and shear zones form in the same experiment, at constant bulk mechanical conditions. Why a kink geometry is favored by the steeply oriented movements is unclear; perhaps it is an effect of different strain rates operating in the different directions. The arrangement is much more commonly developed in bulk simple shear experiments than in triaxial tests, and has only been recorded in sediments with water contents greater than $30 \%$. At Nankai, well-developed deformation bands are known from a mere $260 \mathrm{mbsf}$, indicating that they can form early in the burial history of a sediment.

It seems, therefore, that the deformation bands are an early response to prism shortening, where the shear strains exceed a critical value. This may arise in certain zones of concentrated shear, some of them destined to become thrusts. One reason why kink- and shear zone-like bands become rare below about $700 \mathrm{mbsf}$ may be that the porosities are too reduced for these styles of structure to form. The kink-shear zone arrangement has now been discovered in on-land sedimentary rocks, namely the Pliocene Emi Formation of the southern Boso Peninsula, Japan, but even these cemented rocks still have a porosity of around $30 \%$.

Many shear zones are clearly cross-cut and displaced by faults. This is especially clear in the frontal thrust zone, where deformation bands have been rotated by the folds associated with the thrusting, and displaced by numerous faults. Initiation of faulting seems to reflect some change in mechanical conditions, perhaps fluctuation of fluid pressures, rather than progressive strain. Reduced effective stresses promote intergrain slippage, and may allow high shear strains to be accomplished within very narrow zones of reoriented grains.

The faults show a variety of orientations and senses of displacement, as discussed by Lallemant et al. (this volume), but most in some way seem to be related to tectonic deformation within the prism. However, as reported in Taira, Hill, Firth, et al. (1991), there are a few normal faults that have all the hallmarks of being syn-sedimentary, and the relatively continuous, steep, narrow normal faults found in the lower prism may have formed before the sediment was incorporated into the prism, perhaps as the material passed through the oceanward outer swell. This is in line with the suggestion of Lundberg and Karig (1986) for similar structures seen at Site 582.

\section{Other Structures}

The description of vein structure presented earlier indicates that it is a structure unrelated to the deformation bands, although Karig and Lundberg (1990) suspected a connection. The origin of vein structures has been discussed by a number of workers, such as Cowan (1982), Ritger (1985), Knipe (1986), and Lindsley-Griffin et al. (1990), though it is by no means clear that all these workers are dealing with identical structures. The structures from Site 808 are closely similar to those described by Ogawa et al. (in press), who suggested that a certain combination of extensional stress, elevated pore pressure, and lithology was required. This may have been achieved within the Nankai prism, for example on the outer arcs of thrust-related folds, but it is thought more likely that the vein structures formed before offscraping. The possibility is strongly supported by the occurrence of vein structures at Site 582. Such structures are known to form in slope basin sediments extending through gravitational instability (J. Ashi and Y. Ogawa, pers. comm., 1991; Pickering et al., 1990), and the Nankai examples may well have a similar origin.

The subtle yet curious mottled texture recorded from the décollement could have its origins in bioturbation. On the other hand, the restriction of the texture to the décollement horizon, together with the unlikelihood of bioturbation being preserved here, suggests that the mottled texture is some curious deformation effect, perhaps connected with the overpressuring indicated by the transmission electron microscope analysis (Byrne et al., this volume). That article deals further with the genesis of the décollement textures, and the hydraulic breccia, because both are thought to be closely associated with the history of fluid movements in the Nankal prism.

\section{SUMMARY}

Cores retrieved from Site 808 of the Nankai accretionary prism show a variety of deformation structures, some of them unusually numerous and well developed. A "family of deformation bands" includes kinks, shear zones, and faults, and a range of intermediate types. Both shear zones and faults can show complex substructures and intricate geometric relationships. A common situation is for shear zones, dipping gently in the same direction as bedding, to be accompanied by kink-like bands oriented at a high angle. Faults are dominant in the deeper parts of the prism, reflecting different mechanical conditions. Most of the deformation bands show a reverse sense of movement, recording bulk low-angle shortening of the prism. Rare vein structure, pockets of a hydraulic breccia, and a subtle mottled texture in the décollement indicate localized zones of elevated fluid pressure.

\section{REFERENCES}

Cowan, D.S., 1982. Origin of "vein structure" in slope sediments on the inner slope of the Middle America Trench off Guatemala. In Aubouin, J., von Huene, R., et al., Init. Repts. DSDP, 67: Washington (U.S. Govt. Printing Office), 645-650.

Karig, D.E., and Lundberg, N., 1990. Deformation bands from the toe of the Nankai accretionary prism. J. Geophys. Res., 95:9099-9109.

Knipe, R.J., 1986. Microstructural evolution of vein arrays preserved in Deep Sea Drilling Project cores from the Japan Trench, Leg 57. In Moore, J.C. (Ed.), Structural Fabrics in Deep Sea Drilling Project Cores From Forearcs. Mem.-Geol. Soc. Am., 166:75-87.

Lindsley-Griffin, N., Kemp, A., and Swartz, J.F., 1990. Vein structures of the Peru Margin, Leg 112. In Suess, E., von Huene, R., et al., Proc. ODP., Sci. Results, 112: College Station, TX (Ocean Drilling Program), 3-16.

Lundberg, N., and Karig, D.E., 1986. Structural features in cores from the Nankai Trough, Deep Sea Drilling Project Leg 87A. In Kagami, H., Karig, D.E., Coulbourn, W.T., et al., Init. Repts. DSDP, 87: Washington (U.S. Govt. Printing Office), 797-808. 
Lundberg, N., and Moore, J.C., 1986. Macroscopic structural features in Deep Sea Drilling Project cores from forearc regions. In Moore, J.C. (Ed.) Structural Fabrics in Deep Sea Drilling Project Cores From Forearcs. Mem.-Geol. Soc. Am., 166:13-44.

Maltman, A.J., 1978. Some microstructures of experimentally deformed argillaceous sediments. Tectonophysics, 39:417-436.

1988. The importance of shear zones in naturally deformed wet sediments. Tectonophysics, 145:163-175.

Moore, G.F., Karig, D.E., Shipley, T.H., Taira, A., Stoffa, P.L., and Wood, W.T. 1991. Structural framework of the ODP Leg 131 area, Nankai Trough. In Taira, A., Hill, I., Firth, J.V., et al., 1991. Proc. ODP, Init. Repts., 131: College Station, TX (Ocean Drilling Program), 15-20.

Moore, G.F., Shipley, T.H., Stoffa, P.L., Karig, D.E., Taira, A., Kuramoto, H. Tokuyama, H., and Suyehiro, K., 1990. J. Geophys. Res., 95:8753-8765.

Morgenstern, N.R., and Tchalenko, J.S., 1967. Microscopic structures in kaolin subjected to direct shear. Geotechnique, 17:309-328.

Ogawa, Y., Ashi, J., and Fujioka, K., in press. Vein structures and their tectonic implications for the development of the Izu-Bonin forearc. Proc. ODP, Sci. Results, 126: College Station, TX (Ocean Drilling Program).
Pickering, K.T., Agar, S.M., and Prior, D.J., 1990. Vein structure and the role of pore fluids in early wet-sediment deformation, Late Miocene volcaniclastic rocks, Miura Group, SE Japan. In Knipe, R.J., and Rutter, E.H. (Eds.), Deformation Mechanisms, Rheology and Tectonics. Geol. Soc. Spec. Publ. London, 54:417-430.

Ritger, S.D., 1985. Origin of vein structures in the slope sediments of modern accretionary prisms. Geology, 13:437-439.

Taira, A., Hill, I., Firth, J.V., et al., 1991. Proc. ODP, Init. Repts., 131: College Station, TX (Ocean Drilling Program).

Taira, A., Tokuyama, H., and Soh, W., 1989. Accretion tectonics and evolution of Japan. In Ben-Avraham, Z. (Ed.), The Evolution of the Pacific Ocean Margins: Oxford (Oxford Univ. Press).

Date of initial receipt: 16 October 1991

Date of acceptance: 8 May 1992

Ms 131SR-110 



Plate 1. Photomicrographs of deformation structures recovered from Site 808. 1. Kink bands, visible as darker planar zones. Sample 131-808C-15R-2,7-11 cm, 435 mbsf. Plane-polarized light. 2. Detail of kink band, showing lack of substructure. Sample as in (1). Crossed nicols. 3. Detail of shear zone, showing examples of substructure. Sample 131-808C-10R-2, 35-39 cm, 387 mbsf. Crossed nicols. 4. Deformation band with characteristics of both shear zones and faults. Sample as in (3). Crossed nicols. 5. Detail of vein structure, showing feeble but abrupt grain reorientation. Sample 131-808C-36R-2, 62-65 cm, 640 mbsf. Crossed nicols. 6. Carbonate-bearing fracture. Sample 131-808C-104R-1, 102-104 cm, 1281 mbsf. Crossed nicols. 7. Vertical stylolite-like structure. Sample as in (6). Planepolarized light. 


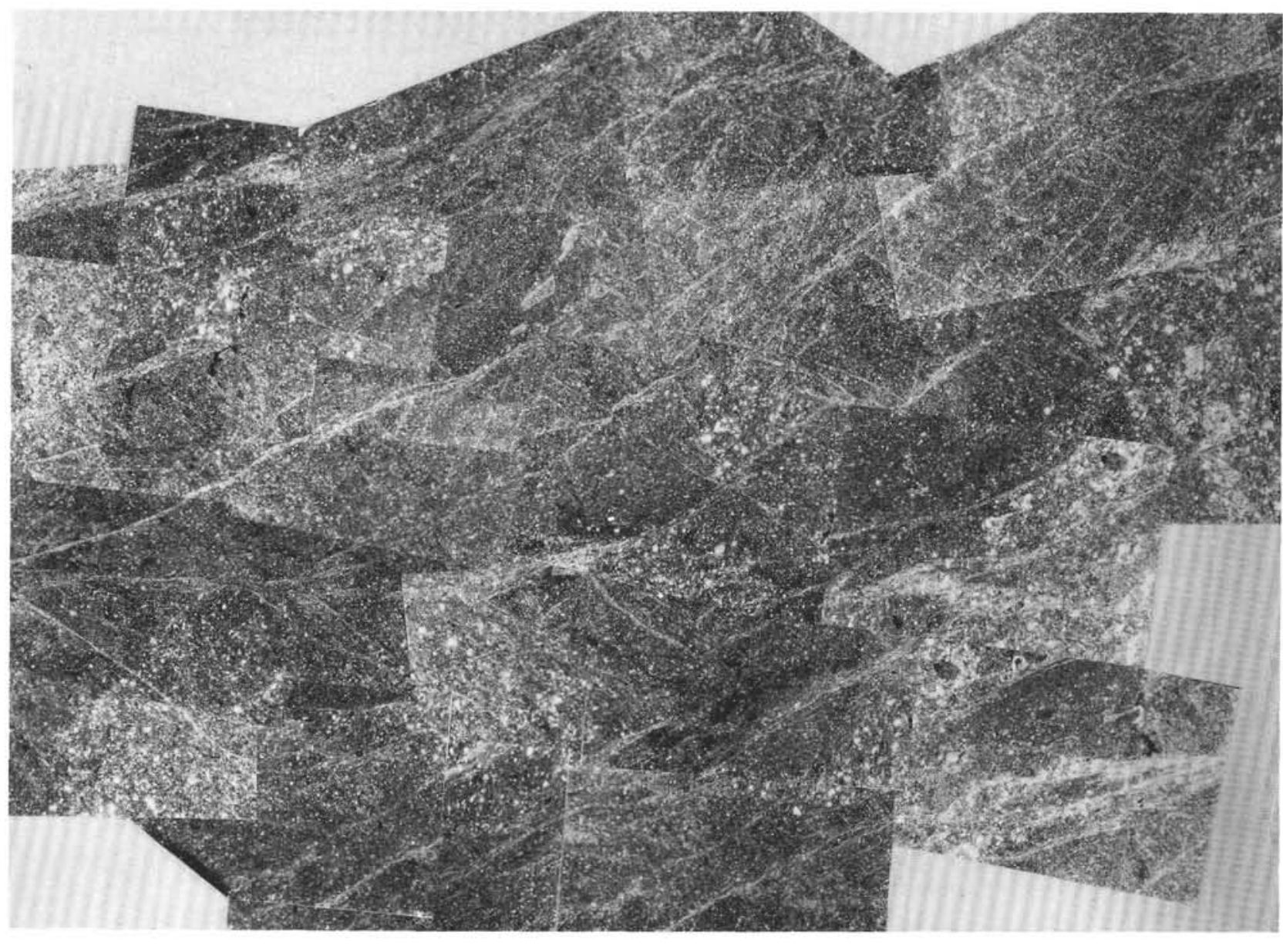

$1 \mathrm{~mm}$

Plate 2. Photographic montage showing relatively complex array of shear zones, in silty clay from a more highly strained horizon. Sample $131-808 \mathrm{C}-25 \mathrm{R}-3$, $31-37 \mathrm{~cm}, 533$ mbsf. Crossed nicols. 


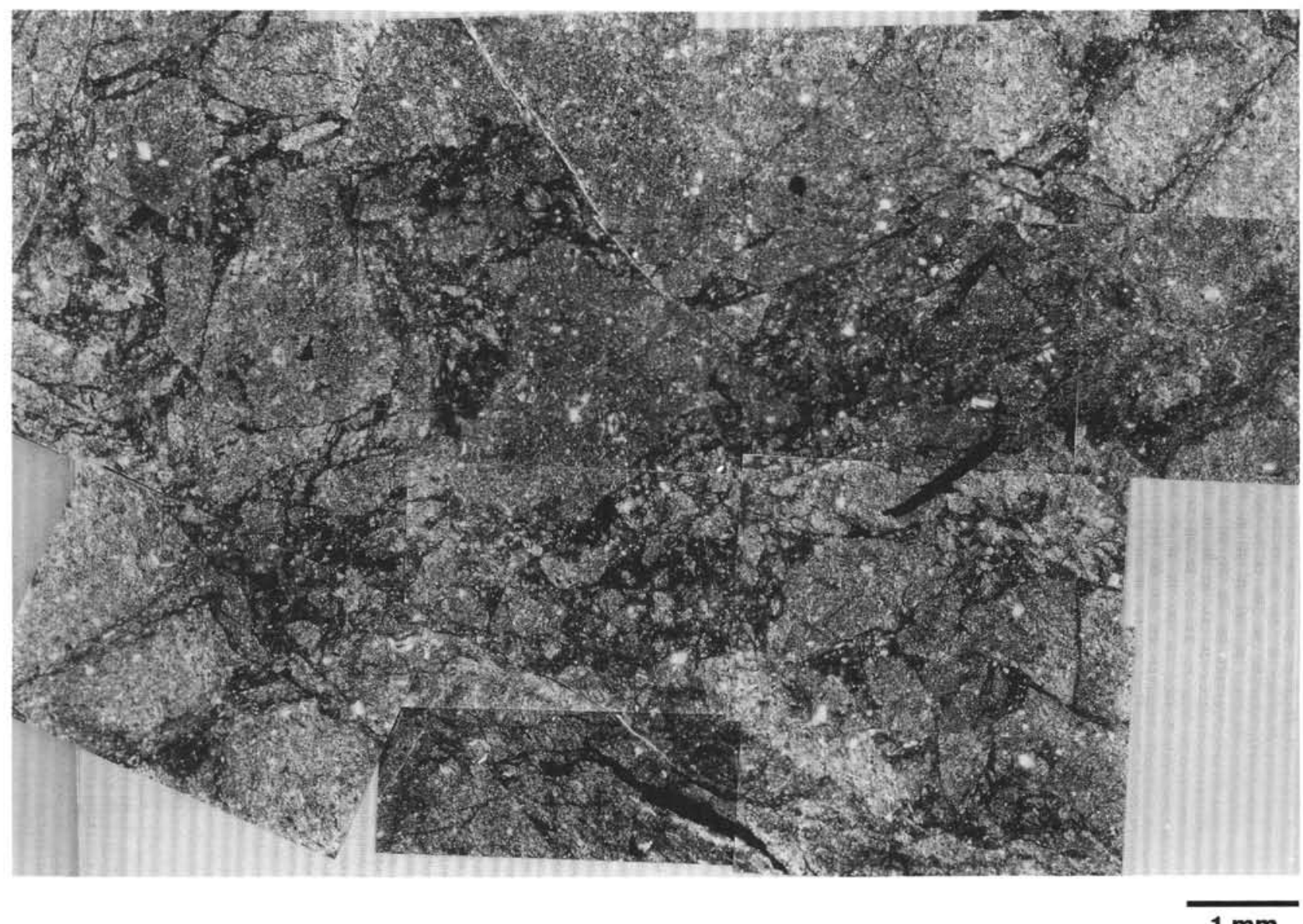

$1 \mathrm{~mm}$

Plate 3. Photographic montage showing patches of "hydraulic breccia," Sample 131-808C-51R-6, 100-103 cm, 788 mbsf. Crossed nicols. 